\title{
Your blog is (the) shit
}

\section{A corpus linguistic approach to the identification of swearing in computer mediated communication}

\author{
Ursula Lutzky and Andrew Kehoe \\ Vienna University of Economics \& Business / Birmingham City University
}

\begin{abstract}
The study of swearing has increased in the last decade, diversifying to include a wider range of data and methods of analysis. Nevertheless, certain types of data and specifically large corpora of computer mediated communication (CMC) have not been studied extensively. In this paper, we fill a gap in research by studying the use of swearwords in blog data, and illustrate ways of identifying swearing in a large corpus by taking context into account. This approach, based on the examination of shared and unique collocates of known expletives, facilitates the distinction of attestations of swearing from non-swearing in the case of polysemous lexemes, and the analysis of overlaps in usage and meaning of swearwords. This work therefore goes beyond basic sentiment analysis and offers new insights into the use of collocation for refining profanity filters, providing innovative perspectives on issues of growing importance as online interaction becomes more widespread.
\end{abstract}

Keywords: swearing, pragmatics, blogs, CMC, collocation

\section{Introduction}

Previous corpus linguistic analyses of swearing have tended to focus on transcribed speech, with several studies, from McEnery et al. (2000a) to Ljung (2009), using the spoken component of the British National Corpus (BNC). This is understandable, given that swearing is often seen as a feature of unplanned, spoken language - "an outlet for frustration and pent-up emotion and a means of releasing nervous energy after a sudden shock" (Crystal 1997: 61). Indeed, later work by McEnery \& Xiao (2004) found expletives to be up to twenty times more frequent in the spoken component of the BNC than in the written component.

In this paper, we examine swearing in a written text format but one which has been shown to exhibit features traditionally associated with spoken discourse: the blog. 
Our analysis is based on a 181 million word sub-corpus of our Birmingham Blog Corpus (http://www.webcorp.org.uk/blogs), which includes both blog posts and reader comments. The commenting feature on blog posts allows some degree of interaction between author and reader and, more frequently, between individual readers. This opens up new possibilities for pragmatic analysis in general and, in this study, for the analysis of swearing in particular. While there have been some corpus linguistic studies of impoliteness in Computer Mediated Communication, or CMC (see e.g. Angouri \& Tseliga 2010, Haugh 2010, and Upadhyay 2010 in the special issue of the Journal of Politeness Research 6 or Hardaker 2010), most of them have focused on formats other than blogs and we intend to fill this research gap by focusing our analysis on this medium.

This study combines a corpus linguistic methodology with a pragmatic analysis. We demonstrate how a large corpus of blogs can be used in the study of swearing, which comprises a potentially infinite inventory of words and phrases and therefore cannot be searched for automatically. We do so by exploring the role context and collocation play in the detection of swearing and in gaining further insights about its use. Our approach is primarily descriptive but has the potential to suggest new solutions to practical, real-world issues encountered in the development and use of CMC platforms, including profanity filtering and the prevention of cyberbullying or "trolling" (e.g. Hardaker 2010). Much of the previous work in these areas has been based upon automatic sentiment analysis which, at its most basic level, involves labelling specific words as either "positive" or "negative" and then searching the corpus for particular concentrations of these words (see e.g. Mishne \& Glance 2006). This is still an area, however, which is somewhat lacking in linguistic sophistication, and we present some of the limitations of automatic sentiment analysis in Section 4 before going on to demonstrate the role collocation can play in refining this approach when dealing with large data collections.

Our aims can therefore be summed up as follows: we aim to combine a pragmatic study with a corpus linguistic methodology, to study the use of "bad language" in blogs, an interactive and communicatively immediate text type, and to explore the role context and collocation can play in identifying and determining the use of swearing in online data. Our work thus offers new perspectives on crucial aspects of online interaction at a time when it is continuing to grow in importance and becoming more widespread. 


\section{Swearing}

As McEnery (2006: 1) states, "[t]he use of bad language is a complex social phenomenon". This is reflected in the range of terms that are used to refer to bad language use. Beers Fägersten (2012: 3-5) gives an overview of such terms, including "bad words, curse words, cuss words, dirty words, four-letter words, expletives, epithets, obscenities, profanity, blasphemy, bawdy language, foul language, rude language, vulgar language, or taboo language" and points out that there is "a trend towards an interchangeability of terms". That is to say that these terms are used as synonyms or near-synonyms to denote bad language use. In addition to the variation in labels, there is disparity with regard to the constructions included in inventories of bad language use, which are more or less openended. This also relates to the fact that they are not restricted to individual words but may comprise more extensive constructions (see Andersson \& Trudgill 1990: 58-59).

In this paper we use the term 'swearing' to refer to expressive uses of bad language. We follow Jay \& Janschewitz (2008: 268) in defining swearing as "the use of taboo language with the purpose of expressing the speaker's emotional state and communicating that information to listeners". That is to say that we do not regard literal uses of taboo words as swearing (e.g. the word shit being used with reference to the excretory system). ${ }^{1}$ On the contrary, we only regard the use of taboo words as swearing when they express emotions, which is the "main purpose of swearing" (Jay \& Janschewitz 2008: 267, see also Ljung 2011). Depending on the context of use, swearing may convey negative feelings, for instance, of anger or frustration, or positive feelings of joy or excitement. Thus, the use of taboo words may act as a means of fostering group membership but it may also insult, offend or offer catharsis by allowing speakers to express pain (Mohr 2013: 13-14).

Jay \& Janschewitz (2008: 269-270) distinguish between 'propositional' and 'nonpropositional' swearing. Propositional swearing is "consciously planned and intentional", whereas nonpropositional swearing is "unintentional, unplanned and uncontrollable" (Jay \& Janschewitz 2008: 270). The latter category is not regarded as polite or impolite due to its automatic nature, triggered for example by sudden emotional outbursts such as surprise. Propositional swearing, on the other hand, can be polite, impolite or neither and it is this type of swearing that we expect to find predominantly in our data given that blogs are a written and therefore planned text type. In any case, the context in which swearing is produced is important and as Butler and Fitzgerald (2011: 
527) note "[t]he use of such language demonstrates a speaker's understanding or treatment of an interaction as an informal and intimate one". It is the situational context and, as we will show below, the collocational environment that determine if a swearing expression carries a positive meaning and enhances social harmony (e.g. fucking as an emphatic intensifier in fucking marvellous) or has a negative connotation to the extent that it may be of a face threatening nature (e.g. you fucking idiot). Consequently, we regard swearwords as taboo expressions "which have the potential to be offensive" (Beers Fägersten 2012: 3) but which do not inherently carry impoliteness as a defining feature.

Previous research introduced categorisations of bad language based on different criteria. McEnery (2006: 30-33, see also McEnery et al. 2000a: 397), for instance, adopts six main headings: swearwords (e.g. fuck), animal terms of abuse (e.g. cow), sexist terms of abuse (e.g. whore), intellect-based terms of abuse (e.g. idiot), racist terms of abuse (e.g. nigger) and homophobic terms of abuse (e.g. queer). In addition to these broad categories, he adopts a more fine-grained categorisation according to the type of bad language use (a scheme originally developed for the Lancaster Corpus of Abuse, see McEnery et al. 2000a, $2000 \mathrm{~b}$ ), which to an extent relates to part of speech; examples include adverbial boosters (e.g. fucking awful), destinational usage (e.g. fuck off!), idiomatic set phrases (e.g. give a fuck), or religious oaths used for emphasis (e.g. by God). Ljung (2011: 29) introduces a classification of swearing based on the distinction between functions and themes, where the "functions are the uses that the swearing constructions are put to by the swearers, while the themes are the different taboo areas that the constructions draw on". The two main subgroups of Ljung's (2011) functions are stand-alones and slot fillers, depending on whether a swearword constitutes an utterance in its own right or forms part of a larger construction. These functions in turn comprise taboo words pertaining to one or several taboo themes, the five main ones of which are the religious/supernatural, scatological, sex organ, sexual activities, and mother (family) themes.

As stated above, the majority of studies on swearing in Present Day English are based on spoken English data, provided for example by the BNC (see e.g. Ljung 2009; McEnery et al. 2000a, 2000b; McEnery \& Xiao 2004: Butler \& Fitzgerald 2011). On the other hand, studies looking in particular at swearing in online data are more infrequent. An example is Thelwall (2008), who studies the social networking site MySpace for attestations of swearing. He bases his study on the demographic information provided on MySpace (the accuracy of which is questionable) to carry out a contrastive analysis of 
US and UK data with the aim of uncovering similarities or differences in the distribution of swearing according to gender. His findings reveal that there "was no significant gender difference in the UK for strong swearing, especially for younger users (16-19)" (Thelwall 2008: 83), in contrast with the US where the incidence was higher for male users.

\section{The Birmingham Blog Corpus and corpus pragmatic approach}

Our study is based on the Birmingham Blog Corpus (BBC), a diachronically-structured collection covering the period 2000-2010 and totalling 630 million words. The corpus is searchable through the WebCorp Linguist's Search Engine (WebCorpLSE) software built by the Research and Development Unit for English Studies (RDUES) at http://www.webcorp.org.uk/blogs (Kehoe \& Gee 2007). In this paper, we focus on a 181 million word sub-section of the corpus downloaded from the WordPress and Blogger hosting sites, which includes both blog posts and reader comments on these posts. This sub-section was built by downloading all posts from each of the blogs featured on the home pages of the hosting sites - known as "Blogs of Note" on Blogger and "Freshly Pressed" on WordPress - and then following links in these posts to other Blogger and WordPress blogs. The resulting corpus contains over 220,000 posts and over 2 million comments (see Kehoe \& Gee 2012 for a fuller description of the corpus and the techniques used to create it).

Blogs have been defined as an online medium, rather than a genre (see e.g. boyd 2006, Herring et al. 2005, Kehoe \& Gee 2012). They are an interactive medium in that they allow for "interaction-at-one-remove" (Nardi et al. 2004); that is to say that blogs are an asynchronous means of computer mediated communication that allows for interactivity on a potentially infinite time scale, with readers being able to comment on a post at any given point in time after its publication on the web. While blogs are a written type of text produced in the graphic code, they have been said to show features traditionally associated with spoken language and communicative immediacy (see Koch 1999). This communicative immediacy means that blogs often contain language innovations which may already have appeared in speech but have not yet found their way into more conventional written texts. For example, Renouf \& Kehoe (2013: 182-183) find the new adjectival use of the word genius (as in genius idea) to be significantly more frequent in the $\mathrm{BBC}$ than in other written corpora. In doing so, they highlighted the fact that blogs are particularly suitable for diachronic analyses as they include more reliable 
date information - for both posts and comments - than most other types of webpage (cf. Kehoe 2006 on the problem of extracting reliable dates from web texts more generally).

This study falls into the area of corpus pragmatics by combining the study of language use with a corpus linguistic methodology, a field of study that has gained increased attention in the last decade (see e.g. Aijmer \& Rühlemann 2014, Jucker 2013, Romero-Trillo 2008). Corpus pragmatic studies are of an empirical nature and focus on types of data that represent naturally-occurring language use. While pragmatic analyses have traditionally been of a qualitative nature and focused on smaller data samples to illustrate certain phenomena, corpus linguistics typically builds on large data samples to ensure representativeness and is associated with quantitative analyses (see Archer et al. 2008: 614, Jucker et al. 2009: 3-4). Furthermore, corpus linguistics has been concerned mainly with studying specific linguistic forms (product, e.g. the form sorry), not least because forms can be searched for with linguistic software, whereas pragmatics has studied linguistic forms but also functions (process, e.g. the speech act of apology). One of the central questions that corpus-pragmaticists have therefore addressed in the last two decades is how the two can be combined.

Jucker (2013) mentions three main approaches to data analysis that have been taken in corpus pragmatics: form-to-function mapping, function-to-form mapping, and communicative expression or metadiscourse analysis. The present study straddles the first two approaches: it is interested in a specific linguistic function - swearing - and wants to gain further insight into the forms used to fulfil this function. On the other hand, it starts out from certain linguistic forms, as will be explained in more detail in the following section, to get a clearer idea of their functions in different collocational environments. By carrying out this analysis, we want to show how collocation can help differentiate between different functions of a form, so as to single out swearing uses and improve the precision of the search output. This is particularly relevant for corpora of a considerable size, such as the BBC, where it is not feasible to exclude unwanted hits manually.

\section{Initial analysis}

As outlined above, our aim was to extract examples of swearing from the BBC by adopting what could, in general terms, be classed as a lexical approach and, more specifically, as a collocational approach. This differentiates our work from studies that 
have made use of automatic sentiment analysis which, while lexical in focus, does not typically take context of occurrence into account, except in very general terms.

One of the earliest studies of blog comments (Mishne \& Glance 2006) makes extensive use of this technique, developing a 'disagreement lexicon' to detect disputes in comment threads. Mishne \& Glance's (2006) study builds upon techniques developed by Nigam \& Hurst (2004) in the market research field to analyse customers' opinions of products as expressed in online reviews: a field which has grown enormously in the decade since that paper was published. In their sentiment analysis of consumer product reviews, Nigam \& Hurst (2004) class the words blurry and crisp as negative and positive respectively in the context of a digital camera review but they do not take immediate textual context into account. We see this as a significant limitation when analysing online data in general and blog data in particular, given that blogs have been shown to be at the forefront of linguistic innovation (cf. Renouf \& Kehoe 2013). This is particularly true of the evaluative words, which form the backbone of automatic sentiment analysis. In addition to well-known examples such as bad and wicked, we find many other instances in the BBC where a word which may be classed as negative in conventional usage is actually used as a positive evaluator: ill, sick, crazy, deadly, fierce, filthy, mean, ridiculous, rude, etc. Consider Examples (1) to (4) below:

(1) He stops off Eastern Michigan University and hits em with an ill rhyme

(2) dude, get the GoChat app! its fuckin awesome, the layout is sick and it works perfectly

(3) Those cookies are so cool! They kind of look like spider webs - I'd like to try them in orange and black for Halloween. And that cake is crazy

(4) This shit is ridiculous [...] more please!

Examples (2) and (4) also contain what may, in a general sense, be classed as 'swearwords': fuckin $(g)$ and shit respectively. However, in neither case is the swearword designed to convey a negative evaluation. The first is an example of what McEnery \& Xiao (2004: 257) in their corpus linguistic analysis of fuck refer to as an "emphatic intensifier' (fucking marvellous is their example). The use of shit in Example (4) is an instance of a less well studied phenomenon. One might assume that the word shit, when used as an evaluator, should always be labelled as negative. However, in our analysis of 
blog data we find that this is not the case, as indicated by Examples (5) to (15) from the BBC:

(5) My job selling car insurance is shit. [negative]

(6) Your blog is shit. [negative]

(7) Your blog is the shit. I love it. [positive]

(8) That is the shit man, completely awesome. [positive]

(9) By the way, your outfit is the shit - fantastic. [positive]

(10) My Mom is the shit and here's why: [lists 6 reasons] I love my Mom. [positive]

(11) What's wrong with Pizza Hut? Some of their pizza is the shit! [positive]

(12) These bloggers really know how to shoot the shit as far as I'm concerned. [positive?]

(13) $[\ldots]$ on the internet where so many use their anonymity to harass, bully, and verbally kick the shit out of people. [negative?]

(14) I should really find myself a good therapist and get my shit together. [neutral]

(15) Drinking cocktails, flirting with handsome men and shit. [neutral]

(16) This is a dress you could wear all spring and summer, and probably in the fall too, with tights and shit. [neutral]

Examples (5) and (6) are indeed unambiguously negative, with the second potentially perceived as impolite. In Example (7), however, the addition of a single word - the definite article - reverses the meaning of the sentence: the shit is a positive evaluation, as reflected by the use of love in the sentence that follows, and given that the word shit here forms part of a compliment (see also Examples (8) and (9)), this example can be classed as a polite usage. Examples (8) to (11) are similarly positive and in most cases there is some other word in the same or adjacent sentence which indicates this: awesome, fantastic, love all reinforce the positive evaluation. ${ }^{2}$ These are the kinds of 'contextual clue' (Renouf \& Bauer 2001: 231) we are capturing when we carry out collocational analyses.

It is not the case, however, that all instances of the phrase the shit can automatically be classed as positive, as illustrated by Examples (12) and (13). These examples both include the shit as part of a longer idiomatic phrase, beginning with the words shoot and kick and meaning chat/gossip and attack respectively. Example (12) is vaguely positive and (13) is loosely negative but these examples illustrate the difficulties 
faced by any automatic sentiment analysis system. Furthermore, Examples (14) to (16), like Example (4) in, illustrate a more general use of shit to mean "stuff", which is neither negative nor positive. This concept is referred to by Ljung (2011: 35) as replacive swearing, whereby a taboo word in its non-literal meaning replaces a non-taboo word.

It is clear, then, that automatic sentiment analysis based on the assignment of words to broad positive and negative categories is of limited benefit when dealing with textual data containing a large proportion of innovative language use. The examples given above illustrate that immediate context of use is vital in determining the specific meaning and illocutionary force of a word. In our study, therefore, context of use is of central importance. Our approach is to begin with a list of words that have been discussed with reference to swearing in other sources and then, through collocational analysis, examine potential overlaps and differences in the usage of these swearwords. This approach is based on the notion that the meaning of a word can be determined by its immediate textual environment or that "[y]ou shall know a word by the company it keeps" (Firth 1957: 11). This principle has been exploited in previous corpus-based research by the RDUES team on the automatic identification of synonyms and other semantic relations in the ACRONYM project (Renouf 1996). That project built a 'collocational profile' for each word (type) in a large newspaper corpus, examining every occurrence of the word and recording the other words occurring within a span of four positions to its left and right. Frequencies of co-occurrence were then recorded in a database, along with statistical measures of significance. By comparing the collocational profiles of words in the database, the ACRONYM software is able to extract pairs of words appearing in similar textual environments (or in similar company in Firthian terms). These word pairs are referred to as 'nyms' and, as Renouf (1996: 171) illustrates, include not only synonym pairs (e.g. luxury, five-star) but also antonym pairs (luxury, no-frills), and 'hyponym-like' relations (luxury, lexus).

Our approach in this paper is related to ACRONYM but with a slightly different emphasis. Instead of extracting semantically-related word pairs from the corpus based on their overlapping collocational environments, we start with a list of words we assume to be semantically-related - swearwords - and use collocational analysis to examine overlaps and differences in their usage and meaning in more detail.

In order to arrive at our initial list of potential swearwords, we consulted two different sources. Our first source was the various profanity filter wordlists designed for 
use by developers of software tools and online communication platforms, e.g. bannedwordlist.com, noswearing.com. Indeed, there are some profanity filters available as plug-ins for the WordPress and Blogger blogging platforms, to allow blog authors to prevent swearing by readers in comments. ${ }^{3}$ One of the most comprehensive wordlists we came across was the "list of 1,300+ English terms that could be found offensive" released by Carnegie Mellon University, ${ }^{4}$ an extract of which is given in Table 1.

Table 1. Extract of profanity filter wordlist from Carnegie Mellon University

\begin{tabular}{llllll}
\hline addict & beast & bombs & christ & communist & criminal \\
adult & bible & bra & christian & conservative & criminals \\
africa & bigger & buried & church & conspiracy & dead \\
asian & black & burn & cigarette & corruption & death \\
assassin & blackout & cancer & cigs & crack & demon \\
assassinate & blow & catholic & cocky & crash & deposit \\
assault & bomb & cemetery & color & creamy & desire \\
babe & bombers & chin & colored & crime & destroy \\
babies & bombing & chinese & coloured & crimes & devil \\
\hline
\end{tabular}

The limitations of such a list are clear from this short extract. No single word in the extract is particularly taboo in itself. It is only in very specific contexts, or in combination with other terms, that a word like black might become offensive. The context of a word must be considered carefully before it can be filtered out or allowed to remain. For this reason, we found the Carnegie Mellon list to be too comprehensive and did not make use of it in our study.

Our second source of swearwords in building our initial wordlist was the findings of previous linguistic studies on swearing, including Thelwall's (2008) study of MySpace, Hughes (1998), McEnery (2006), and Beers Fägersten (2012). Through these sources, we finally arrived at a list of 80 swearwords which we decided to use as the starting point for our study (see Appendix for full list). ${ }^{5}$ The searches conducted for these words were caseinsensitive and we accounted for differences in spelling, number and inflection by designing our search queries carefully in WebCorpLSE. In some cases, wildcard search was sufficient (e.g. fuck*) but, in others, we had to develop more specific queries (as shown in the Appendix). We used the "refine query" option in WebCorpLSE to check for cases where wildcard search would be too "wild". For example, arse* would have matched arsenal, arsenic, Arsene, Arsenio, etc. as well as the intended target words. In addition, this wildcard search would not have matched the US variant ass (and related 
words). For these reasons, we used a more specific query to find examples of this swearword (see Appendix). The top 20 most frequent words in our initial list are given in Table 2. This table is ordered by overall frequency in the BBC sub-corpus. The specific frequencies of each word in posts and comments are also given, and these are discussed in more depth in Section 6. In what follows, we refer to each example by the headword given in the left column in the Appendix.

Table 2. The 20 most frequent (potential) swearwords in the BBC sub-corpus (frequencies per million words)

\begin{tabular}{llll}
\hline & Posts & Comments & Overall \\
\hline god & 692.14 & 608.62 & 652.34 \\
jesus & 262.53 & 141.63 & 204.93 \\
hell & 116.73 & 117.90 & 117.29 \\
*shit* & 115.68 & 114.92 & 115.32 \\
christ & 138.53 & 76.87 & 109.15 \\
fuck* & 112.03 & 101.42 & 106.98 \\
*damn* & 85.14 & 127.21 & 105.18 \\
arse/arses/arsed/arsehole*/ass/asses/assed/asshat*/asshole* & 83.54 & 106.86 & 94.65 \\
crap* & 59.73 & 85.85 & 72.18 \\
suck/sucks/sucker/suckers & 53.05 & 86.37 & 68.93 \\
omg & 13.31 & 101.22 & 55.19 \\
gay & 40.16 & 40.83 & 40.48 \\
cow/cows & 31.03 & 40.90 & 35.73 \\
butt/butts/butthead/buttheads/butthole/buttholes & 28.26 & 37.89 & 32.85 \\
piss* & 32.48 & 32.45 & 32.47 \\
bitch/bitches/biatch/biatches & 29.30 & 32.07 & 30.62 \\
idiot/idiots & 23.11 & 33.65 & 28.13 \\
balls & 29.50 & 24.76 & 27.24 \\
screw/screws/screwed/screwing & 25.37 & 26.00 & 25.67 \\
pig/pigs & 24.36 & 26.67 & 25.46 \\
\hline
\end{tabular}

One thing that stands out in Table 2 is the proliferation of words with religious associations towards the top of the list: god, jesus, hell, christ; possibly also damn and omg (meaning oh my god; we return to omg in Section 6). The most frequent word in our list, god, is included as a swearword in several of the previous studies discussed above, and would fall into Ljung's (2011) 'religious' taboo theme. Clearly, though, it and the other religious words are highly context-dependent, as illustrated by Examples (17) to (25) from the BBC sub-corpus: 
(17) I know that Jesus Christ was the Son of God, the Redeemer, and that He truly did atone for our sins and make forgiveness, hope, and happiness possible

(18) Holy shit and jesus christ in a rowboat, do these bastards think I am made of money?

(19) So Joel belongs to the greater Church of Jesus Christ. Well where the heck is that?

(20) I am no mathalete, or anything, but my calculations are indicating that purple flying pigs will ice skate on a lake of frozen gold in hell before I pay that much for this car.

(21) Get the hell back in your cage!

(22) Crap like this is exactly why you will burn in hell.

(23) I strongly believe in God and try to portray it in every form of art

(24) Who was that miserable woman? Thank god she's not around any more!

(25) You know what no matter what politics or religion you espouse, no matter what nation you're living in or what nation you're from, for one day a year at least out of life, people of good will ought to set aside a time to step back, open their eyes and say: 'God damn it. this is one hell of a world'

Here we see three instances each of jesus christ (Examples (17) to-(19)), hell (Examples (20) to (22)) and god (Examples (23) to (25)). Within each group of three there are examples of the term in question being used in a religious context and as part of an instance of swearing. There is a little ambiguity in some of the examples - e.g. in Example (19) Jesus Christ is used in reference to a church, i.e. in a literal sense, but is followed by the mild swearword heck (not included in our list). However, in most cases there are clear indicators in the immediate context of use, e.g. God, Redeemer, atone and sins in Example (17); shit and bastards in Example (18). These are the indicators we are counting and summarising in the collocational analysis we carry out in the following section to distinguish literal from expressive uses.

\section{Collocational analysis}

The first step in our analysis was to produce a collocational profile for each of the potential swearwords in our initial list. WebCorpLSE was used to extract the top 100 
collocates for each word at span 4 (i.e. four words to the left of the word and four words to the right). ${ }^{6}$ The top 25 collocates of bastard are given in Table 3 as an example.

Table 3. Top 25 collocates of bastard (span 4)

\begin{tabular}{llll}
\hline Collocate & Collocate frequency & Co-occurrence frequency & z-score \\
\hline poor & 19,120 & 64 & 37.77 \\
little & 218,057 & 182 & 29.56 \\
Jimmy & 2,522 & 32 & 28.55 \\
Mr & 11,166 & 35 & 24.31 \\
those & 193,619 & 137 & 22.86 \\
sick & 14,335 & 35 & 22.37 \\
fat & 10,773 & 32 & 22.34 \\
dirty & 5,961 & 27 & 21.46 \\
lazy & 5,988 & 27 & 21.45 \\
rich & 11,374 & 29 & 19.79 \\
fucking & 6,997 & 23 & 17.54 \\
greedy & 1,093 & 19 & 17.33 \\
evil & 12,179 & 26 & 17.21 \\
cheating & 1,657 & 18 & 16.05 \\
rat & 1,603 & 17 & 15.13 \\
selfish & 2,698 & 17 & 14.57 \\
sneaky & 904 & 16 & 14.53 \\
miserable & 2,817 & 17 & 14.51 \\
child & 30,397 & 32 & 14.23 \\
cheap & 9,570 & 20 & 13.95 \\
murdering & 359 & 15 & 13.82 \\
who & 323,214 & 123 & 12.94 \\
lucky & 24,836 & 26 & 12.59 \\
lying & 5,278 & 16 & 12.51 \\
universe & 6,176 & 16 & 12.15 \\
\hline
\end{tabular}

Table 3 is sorted by z-score, a measure of statistical significance which takes into account the frequency of the node (the swearword) and of each collocate in relation to corpus size. So, for example, although poor collocates with bastard less frequently than little does (64 times versus 182), it is given a higher z-score because poor is a much less frequent word than little $(19,120$ occurrences versus 218,057). Both of these words and many of the others in the top 25 are adjectives commonly associated with the noun bastard(s). Whilst the top collocate, poor, can be used in combination with bastard to express sympathy, the majority of adjectives in the list appear to be negative evaluators. The caveats we outlined in the previous section do of course apply although, interestingly, one of the words we discussed above, sick, appears to remain entirely negative when associated with bastard. 
In all but six of the 35 span 4 co-occurrences, sick actually appears as an immediate lefthand collocate of bastard (i.e. at span 1). In four of the six exceptions, the two words are separated by an additional modifier: twisted twice, fuckin' and degen (i.e. degenerate) once each. Example (26) is typical of the majority:

(26) Unlike my parents, I live in almost daily fear that if I relax my vigilance just one second, some sick bastard will take my child from me.

Two collocates in Table 3 require further explanation: Jimmy and $M r$. both refer to a blogger known as "Jimmy Bastard" who was active around 2009-10. He ran his own popular blog hosted on Blogger ${ }^{7}$ and was also a frequent commenter on blog posts written by other people on both Blogger and WordPress. It was in the latter context that he was sometimes referred to as "Mr Bastard" by his fellow commenters.

After similar collocational profiles had been built for each of the potential swearwords in our initial list, we took each word in turn and compared its top 100 collocates with the top 100 collocates of all the other words combined. Through this process we were able to uncover (i) the shared collocates of the swearwords, indicating overlapping usage, and (ii) the unique collocates of each, suggesting differences in usage and meaning.

\subsection{Shared collocates}

Figure 1 is a diagrammatic representation of shared collocates in our BBC sub-corpus. Each row represents one of the potential swearwords, each column represents a collocate, and shaded boxes indicate where swearwords share collocates. The number at the bottom of each column indicates how many of the swearwords share that collocate. For example, the first collocate, $a$, is shared by 54 of the swearwords (bastard, bimbo, bitch, bloody, etc.). ${ }^{8}$ Figure 1 shows the top 33 shared collocates (all those collocates shared by 17 or more swearwords). We will make several initial observations about the shared collocate results below, as indicated by coloured highlighting in Figure 1.

Firstly, several of the shared collocates (columns) are themselves taboo words: fucking, ass, shit, fuck. The first of these - fucking - collocates with 31 of the 54 swearwords in our list. What this seems to reflect is that writers in our blog corpus frequently use multiple swearwords in sequence or in close proximity to each other. We 
have already seen an example of this in Table 3 with fucking as a significant collocate of bastard.

Secondly, the taboo words in our list tend to be associated with males more so than with females. In Figure 1 we see his as a shared collocate of 27 words, together with he and he's (26 each), and him (17). Of course, we cannot tell from the shared collocate list alone whether the male is the speaker or the referent but this list does provide a useful signpost to guide us in our analysis.

We see evidence of fixed phrases where either up or off collocates with a swearword (compare the category "destinational usage" mentioned in Example (2), McEnery et al. 2000a, 2000b): fuck off, fuck up, balls up, cock up, etc. There are also several intensifiers in the shared collocate list, which contribute to the expression of emotions: such (a), big, complete, total. An extreme case is Example (27), which is taken from a blog post reviewing a book:

(27) It goes up and then down and there are times when you want to punch both of them - Cathy for being too gullible and Jewel for being such a complete and total bitch.

In the context of swearing, we have found that little (a shared collocate of 18 swearwords) can also function as an intensifier. We would argue that there is no difference in intensity between Examples (28) and (29):

(28) Will Folks claimed they had an extramarital affair and a pal of mine with ties to a newly elected state representative (his wife) claims she is a big 'skank' who is 'sleeping with everybody'.

(29) Paula knows how I feel about that little skank and she would never, ever do that to me, right?

One final shared collocate worthy of attention is like, which is shared by 48 of the words in our list. Initially, we were rather puzzled by this until we looked more closely at the concordance examples. After analysing examples from the corpus in depth, we concluded 
that the uses of like can be grouped into three main categories and that collocation with like can be regarded as a signal that a taboo word is used in an instance of swearing:

i. To act like a(n) idiot/moron/asshole/douche/etc.

ii. To feel/look/treat like shit/crap

iii. Quotative like: e.g. I was like WTF [“What The Fuck?"]

In Figure 1, we also see that there are some words (rows) with fewer shared collocates than others. The examples that stand out are balls, bloody, christ, cow, dyke, god, hell, ho, homo, jesus, omg, pig, queer, swine, and tart. Several of these have religious associations, and many of the others are highly polysemous so it is perhaps unsurprising to see that they demonstrate fewer overlaps in usage and meaning than core swearwords such as fuck and shit. However, it is useful to see this confirmed diagrammatically in Figure 1 and we analyse these words in more depth in Section 5.2. 


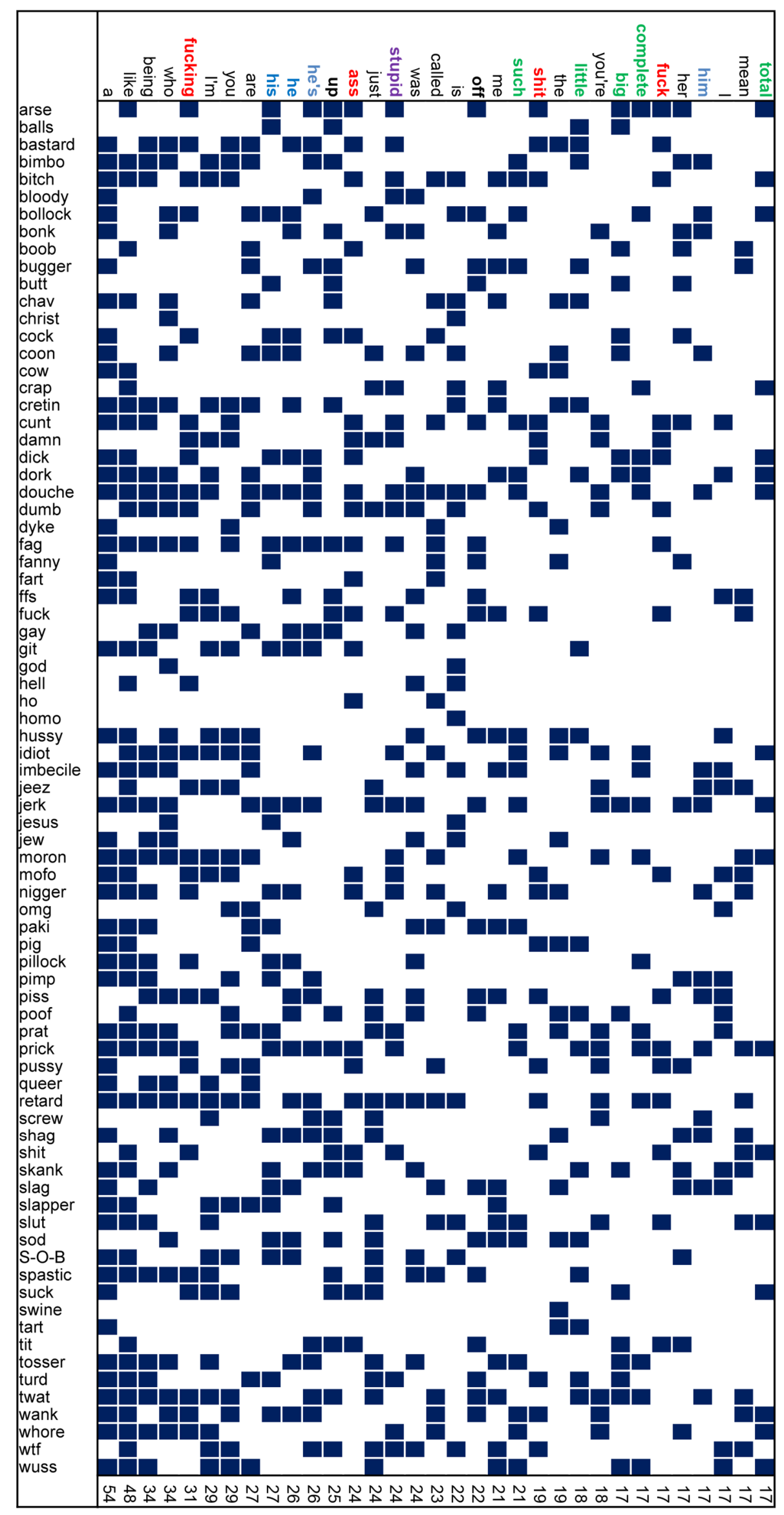

Figure 1. Shared collocates in the BBC sub-corpus 


\subsection{Unique collocates}

Figure 2 shows the unique collocates of a selection of the words from Figure 1 with the fewest shared collocates. The words included in Figure 2 are those with the largest number of unique collocates (shown in parentheses next to the word at the top of each group). For example, homo has 72 unique collocates or, in other words, 72 of its top 100 significant collocates $(72 \%)$ are not shared with any other taboo word.

In each group in Figure 2, the unique collocates are sorted by strength of collocation with the headword (with the top 20 unique collocates listed). The strongest unique collocate of homo - sapiens - along with the other unique collocates in that group offer a clear indication of the specific, non-swearing use of homo in our data. The same is true of tart, which has 66 unique collocates relating largely to baking, and swine, with 60 unique collocates relating in particular to swine flu. The headword balls has 56 unique collocates, relating to sports and other kinds of physical ball. Based on this collocational information, it would seem that these mild swearwords are rarely used for that purpose at all in our corpus.

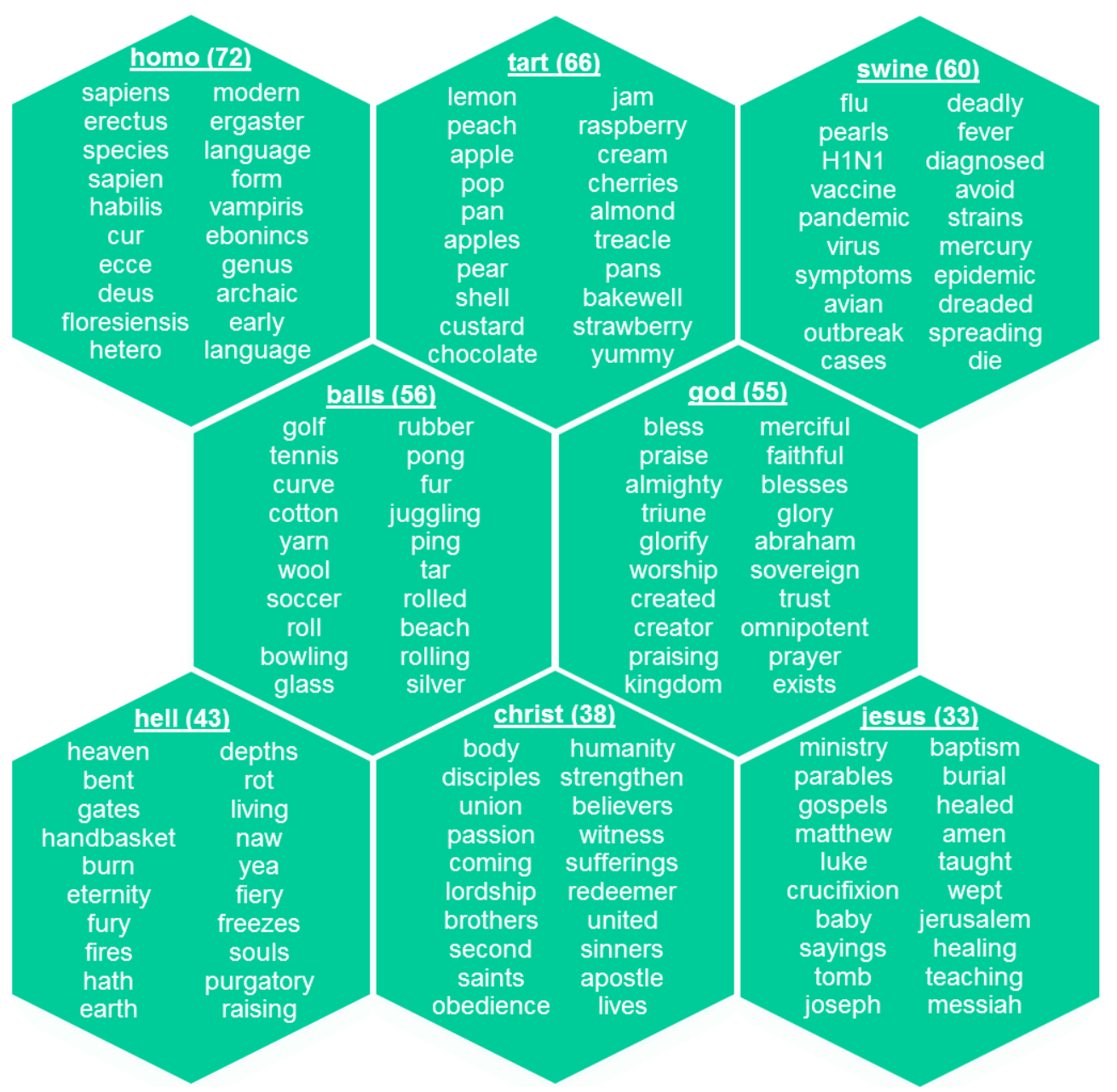

Figure 2. Unique collocates in the BBC sub-corpus 
Turning to the religious words in Figure 2, god (55), hell (43), christ (38) and jesus (33) all have a large proportion of unique collocates, with hell particularly noteworthy for the number of fixed phrases evident in its unique collocate list: hell bent, hell in a handbasket, burn in hell, hell hath no fury, hell on earth, depths of hell, rot in hell, a living hell, hell yea/naw [yes/no], when hell freezes over, hell raising/raising hell, etc. It is also interesting to see that christ and jesus, though seemingly closely related, have many unique collocates when compared with each other.

It would seem, then, that the religious swearwords are used primarily for nonswearing purposes in our corpus. That is to say that words such as god, hell, christ and jesus are used mainly when discussing religion as a topic. In order to investigate this further, we examined the distribution of all swearwords between blog posts and reader comments, the results of which can be found in the following section.

\section{Posts versus comments}

Our initial assumption when comparing posts and comments was that topic-related words would be more likely to be found in the post whereas insults and swearing would be more likely in the more informal and conversational comments section.

Overall, we found the combined frequency of all potential swearwords in our list to be similar in posts and comments, with 2,290 per million words in the former and 2,325 per million words in the latter. However, it was when we used the log-likelihood statistic to compare the frequencies of individual words between posts and comments that we began to detect differences. This statistic is often used in corpus linguistic analyses to extract 'key words' from a corpus or sub-corpus by comparing it against a larger reference corpus. We have used log-likelihood analyses previously to extract topic-related words from individual blog posts and comment threads by comparing these against the whole BBC sub-corpus (Kehoe \& Gee 2012). In this paper, our comparison is between posts and comments, and the first set of results is given in Table 4. 
Table 4.: Key swearwords in posts

\begin{tabular}{llll}
\hline & Posts $(\mathbf{p m w})^{*}$ & Comments (pmw) & Log-Likelihood \\
\hline jesus & 262.53 & 141.63 & $3,307.76$ \\
christ & 138.53 & 76.87 & $1,612.41$ \\
god & 692.14 & 608.62 & 485.15 \\
fuck & 112.03 & 101.42 & 47.64
\end{tabular}

* pmw: per million words

As shown in Table 4, the word from our list which is most 'key' in posts when compared against comments is jesus, followed by christ and god. In order to explain why these three words are significantly more frequent in posts than in comments, we returned to the corpus and examined the blog posts in which these words are particularly frequent. An example with a high concentration of the words is a post entitled "Demythologizing the Divide between Barth and Bultmann" on an academic blog called The Fire and the Rose. ${ }^{9}$ This post has only one comment, containing none of the words from our list. However, the post itself is over 7,000 words long and contains 218 instances of the word god, plus 18 instances of jesus and 13 of christ. Using the WebCorp Live Wordlist Tool ${ }^{10}$ we see that god is the most frequent non-stopword in this text. The Wordlist tool also highlights other frequent words which indicate the topic of this text: barth, bultmann, revelation, doctrine, trinity, theology, humanity, divine, etc. That is to say that an examination of the wider context - going beyond the level of the collocational window to whole text level tells us that the religious terms are unlikely to be used as swearwords in this case. We are still making use of automated corpus linguistic tools in our pragmatic analysis but we are doing so at a wider level.

If we now turn to the swearwords which are more 'key' in comments when compared against posts (Table 5), we see that one word in particular stands out: omg, which is found almost eight times more often in comments than in posts in our corpus and is given a high log-likelihood score as a result. ${ }^{11}$ 
Table 5. Key swearwords in comments

\begin{tabular}{llll}
\hline & Posts $(\mathbf{p m w})^{*}$ & Comments (pmw) & Log-Likelihood \\
\hline omg & 13.31 & 101.22 & $-7,014.75$ \\
damn & 85.14 & 127.21 & -762.01 \\
suck & 53.05 & 86.37 & -730.30 \\
crap & 59.73 & 85.85 & -427.68 \\
arse & 83.54 & 106.86 & -259.80 \\
boo & 11.73 & 20.77 & -231.61 \\
idiot & 23.11 & 33.65 & -178.54 \\
jeez & 2.58 & 6.22 & -141.73 \\
butt & 28.26 & 37.89 & -127.70 \\
cow & 31.03 & 40.90 & -123.28 \\
fart & 6.83 & 11.77 & -120.37 \\
wtf & 10.44 & 15.74 & -97.75 \\
douche & 6.65 & 10.80 & -90.12 \\
dumb & 19.93 & 26.66 & -88.41 \\
ho & 12.36 & 17.14 & -70.44 \\
moron & 6.04 & 9.48 & -69.52 \\
bugger & 5.27 & 8.39 & -65.01 \\
retard & 5.10 & 7.57 & -44.05 \\
tit & 6.49 & 8.98 & -36.62 \\
bastard & 13.81 & 16.82 & -26.84 \\
* pmw: per million words & &
\end{tabular}

This word was of particular interest to us as it is an abbreviation of oh my god yet it behaves in the completely opposite way to god, which, as we saw in Table 4, is significantly more frequent in posts. For this reason, we wanted to analyse omg in more depth. We began our analysis of omg by examining various dictionary definitions of $\mathrm{Oh}$ My God, the phrase from which it derives. Several of these are given below:.

i. http://www.oed.com/

The vocative, as ah God, oh God, my God, good God, etc., is used to express strong feeling or excitement.

ii. http://dictionary.cambridge.org/

used to emphasize how surprised, angry, shocked, etc. you are:

My God, what a mess!

Oh my God, I've never seen anything like it!

iii. http://www.macmillandictionary.com/ 
God - interjection

used for expressing strong feelings such as anger, surprise, or worry. Some people consider this expression offensive.

God! Would you shut up for a minute?

My God, you scared me!

Oh my God, are you all right?

What is noticeable here is how the interjection is often associated with strong negative emotions such as anger, shock and worry. One dictionary - Macmillan - even goes as far as to say that "[s]ome people consider this expression offensive". Intuitively, we did not feel that the abbreviated form omg carries the same associations but we wanted to test this empirically using our corpus. To do so, we looked more closely at the span 4 collocates of omg in comments only (Table 6).

Table 6. Top 25 collocates of $\mathrm{omg}$ in comments (span 4)

\begin{tabular}{lll}
\hline Collocate & $\begin{array}{l}\text { Co-occurrence } \\
\text { Freq }\end{array}$ & Z-score \\
\hline hilarious & 148 & 62.43 \\
love & 950 & 41.17 \\
funny & 201 & 39.07 \\
lol & 234 & 38.67 \\
cute & 206 & 38.55 \\
soooo & 59 & 33.79 \\
awesome & 213 & 33.26 \\
laughing & 75 & 29.99 \\
amazing & 217 & 29.67 \\
laughed & 61 & 29.56 \\
totally & 149 & 28.99 \\
hysterical & 36 & 28.59 \\
lmao & 34 & 26.98 \\
freaking & 39 & 26.01 \\
adorable & 81 & 25.13 \\
sooo & 44 & 24.03 \\
looks & 205 & 23.66 \\
sooooo & 33 & 23.55 \\
gorgeous & 122 & 22.61 \\
xo & 71 & 21.36 \\
xx & 69 & 20.44 \\
cutest & 27 & 19.15 \\
congrats & 83 & 18.02 \\
\end{tabular}




\begin{tabular}{lll} 
xoxo & 49 & 16.78 \\
hugs & 89 & 16.74 \\
\hline
\end{tabular}

It is clear from Table 6 that the strongest collocates of omg are all overwhelmingly positive, relating in particular to things that the writer finds funny or cute. We have noticed that omg frequently appears in comments on posts containing photographs and that it tends to be the first word in a sentence, as in Examples (30) to (33):

(30) $O M G$ that costume is hilarious.

(31) $O M G$, I love your hair!

(32) $O M G$ that backdrop is AMAZING!!!

(33) $O M G$ it's official, you and your husband are the cutest couple ever!!!

These are very different from the contexts in which we find the word god, and there appears to be very little overlap in the usage of god and omg in our corpus. In fact, of their top 100 span 4 collocates, omg and god have only one in common - believe - and even this one shared collocate is used differently in each case. When believe collocates with god it is usually in the phrase believe in god, whereas the collocation with omg is usually a variant of omg, I can't believe [x]. This, in addition to our findings presented above, supports our conclusion that while god is mainly used in a literal sense in our data, omg almost exclusively appears in the context of expressing strong positive emotions.

\section{Conclusion}

This study approached the topic of swearing in blog posts and comments, with the intention of providing further insights into a topic that has not been investigated extensively in online data. To this end, we linked the study of the pragmatic phenomenon of swearing with a corpus linguistic methodology, showing in particular how a large corpus of written but communicatively immediate online language data can be used in the analysis of a potentially open-ended and expressive category of pragmatic markers.

In contrast to the majority of previous studies on swearing, we based our analysis on a broad definition of swearing, indicating that swearwords could potentially have positive, negative or neutral connotations. Thus, we regard swearing as the speaker's attempt to express their diverse emotions through the use of "bad" or taboo language and 
to (potentially) convey these feelings to their interlocutor (see Jay \& Janschewitz 2008, Ljung 2011).

We have demonstrated that in order to gain further understanding of a particular use of a swearword, it is essential to consider the context in which it appears. In this study, we therefore examined the company that swearwords keep by carrying out a focused analysis of their shared and unique collocates. This allowed us to obtain results in a semiautomatic manner, which is useful given that the size of the Birmingham Blog Corpus precludes a comprehensive manual analysis. Our study revealed that there is a group of "core" swearwords which are often used in close proximity to each other (e.g. fuck, shit, crap), together with a small set of peripheral swearwords which appear to be rarely used for that purpose at all in our data (e.g. homo, tart, swine). Between these two extremes there are many other words - several relating to religious themes (e.g. jesus, christ, god) - whose categorisation requires careful consideration of context. Further work is necessary to analyse all of these words in depth, but we believe that the innovative collocational approach we have presented in this paper, combining the study of unique and shared collocates, offers significant advantages in the pragmatic analysis of large corpora and that the information gained in this and future studies of swearing in online data will allow the refinement of profanity filters to sift out potentially offensive language use. 


\section{Notes}

1. For a discussion of taboo and taboo words, see Ljung (2011: 5-8).

2. Example (11) is an exception in that there are no specific clues other than the juxtaposition of the two sentences, where the second is contrasted with the word wrong in the first.

3. The use of such plug-ins would, of course, prevent the occurrence of swearwords in a corpus built from WordPress and Blogger. However, the fact that we find many thousands of examples in comments indicates that such plug-ins are not widely used.

\section{4. http://www.cs.cmu.edu/ biglou/resources/bad-words.txt}

5. As this list is based on several studies on swearing, its composition reflects the diversity in approaches taken in these studies, to the extent of including forms such as $O M G$, which may traditionally not be regarded as examples of swearing. We further discuss the specific example of $O M G$ in Section 6.

6. Although this window would miss some of the contextual clues illustrated in Examples (17) to (25) - e.g. atone and sins in Example (17) - we chose span 4 as it has been shown to offer meaningful results in previous RDUES projects. In a corpus as large as ours, there will be other examples where atone and sins do appear within four words of jesus and/or christ.

\section{7. http://nevermindthebollix.blogspot.co.uk/}

8. To some extent there are grammatical restrictions on collocation but this effect is reduced by considering span 4 rather than span 1. For example, $a$ would be less likely to collocate with words beginning with a vowel at span 1, but this is not impossible at span 4 .

\section{9. http://fireandrose.blogspot.co.uk/2008/06/demythologizing-divide-between-barth.html}

10. http://www.webcorp.org.uk/live/wdlist.jsp

11. The scores are negative in this table as we are using the opposite end of the scale used in the previous table (i.e. viewing the comparison in the other direction). 


\section{References}

Aijmer, K., \& Rühlemann, C. (Eds.) (2014) Corpus Pragmatics. A Handbook. Cambridge: Cambridge University Press.

Andersson, L., \& Trudgill, P. (1990). Bad Language. Oxford: Basil Blackwell.

Angouri, J., \& Tseliga, T. (2010). “you HAVE NO IDEA WHAT YOU ARE TALKING ABOUT!" From e-disagreement to e-impoliteness in two online fora. Journal of Politeness Research, 6(1), 57-82.

Archer, D., Culpeper, J., \& Davies, M. (2008). Pragmatic annotation. In A. Lüdeling \& M. Kytö (Eds.), Corpus Linguistics: An International Handbook (pp. 613-641). Berlin: Mouton de Gruyter.

Beers Fägersten, K. (2012). Who's Swearing Now? The Social Aspects of Conversational Swearing. Newcastle upon Tyne: Cambridge Scholars Publishing.

boyd, d. (2006). A blogger's blog: Exploring the definition of a medium. Reconstruction, 6(4). Retrieved from http://www.danah.org/papers/ABloggersBlog.pdf (last accessed February 2016).

British National Corpus (BNC), XML Edition. (2007). Distributed by Oxford University Computing Services on behalf of the BNC Consortium.

Butler, C. W., \& Fitzgerald, R. (2011). "My f***ing personality": Swearing as slips and gaffes in live television broadcasts. Text \& Talk, 31(5), 525-551.

Culpeper, J. (2011). Impoliteness. Using Language to Cause Offence. Cambridge: Cambridge University Press.

Crystal, D. (1997). The Cambridge Encyclopedia of Language (2nd ed.). Cambridge: Cambridge University Press.

Firth, J. R. (1956). Papers in Linguistics 1934-1951. London: Oxford University Press.

Hardaker, C. (2010). Trolling in asynchronous computer-mediated communication: From user discussions to academic definitions. Journal of Politeness Research, 6(2), 215-242.

Haugh, M. (2010). When is an email really offensive?: Argumentativity and variability in evaluations of impoliteness. Journal of Politeness Research, 6(1), 7-31.

Herring, S. C., Scheidt, L. A., Wright, E., \& Bonus, S. (2005). Weblogs as a bridging genre. Information Technology and People, 18(2), 142-171.

Hughes, G. (1998). Swearing: A Social History of Foul Language, Oaths and Profanity in English. Oxford: Blackwell.

Jay, T., \& Janschewitz, K. (2008). The pragmatics of swearing. Journal of Politeness Research, 4, 267-88.

Jucker, Andreas H., Schreier, D., \& Hundt, M. (2009). Corpus linguistics, pragmatics and discourse. In A. H. Jucker, D. Schreier \& M. Hundt (Eds.), Corpora: Pragmatics and 
Discourse. Papers from the 29th International Conference on English Language Research on Computerized Corpora (ICAME 29) (pp. 3-9). Amsterdam: Rodopi.

Jucker, Andreas H. (2013). Corpus pragmatics. In J.-O. Östman \& J. Verschueren (Eds.), Handbook of Pragmatics (pp. 1-18). Amsterdam: John Benjamins.

Kehoe, A. (2006). Diachronic linguistic analysis on the web using WebCorp. In A. Renouf \& A. Kehoe (Eds.), The Changing Face of Corpus Linguistics (pp.297-307). Amsterdam: Rodopi.

Kehoe, A., \& Gee, M. (2007). New corpora from the web: Making web text more "text-like"'. In P. Pahta, I. Taavitsainen, T. Nevalainen \& J. Tyrkkö (Eds.), Studies in Variation, Contacts and Change in English 2: Towards Multimedia in Corpus Studies. VARIENG E-journal. Helsinki: University of Helsinki. Retrieved from http://www.helsinki.fi/varieng/journal/volumes/02/kehoe_gee (last accessed February 2016).

Kehoe, A., \& Gee, M. (2012). Reader comments as an aboutness indicator in online texts: Introducing the Birmingham Blog Corpus. In S. Oksefjell Ebeling, J. Ebeling \& H. Hasselgård (Eds.), Studies in Variation, Contacts and Change in English 12: Aspects of Corpus Linguistics: Compilation, Annotation, Analysis. Proceedings of ICAME 32, VARIENG E-journal. Helsinki: University of Helsinki. Retrieved from http://www.helsinki.fi/varieng/series/volumes/12/kehoe gee/ (last accessed February 2016).

Koch, P. (1999). Court records and cartoons. Reflections of spontaneous dialogue in early Romance texts. In A. H. Jucker, G. Fritz \& F. Lebsanft (Eds.), Historical Dialogue Analysis (pp. 399-429). Amsterdam: John Benjamins.

Ljung, M. (2009). The functions of expletive interjections in spoken English. In A. Renouf \& A. Kehoe (Eds.), Corpus Linguistics: Refinements \& Reassessments (pp. 155-171). Amsterdam: Rodopi.

Ljung, M. (2011). Swearing. A Cross-cultural Linguistic Study. Basingstoke: Palgrave Macmillan. McEnery, A. (2006). Swearing in English. Bad Language, Purity and Power from 1586 to the Present. London: Routledge.

McEnery, A., Baker, J. P., \& Hardie, A. (2000a). Assessing claims about language use with corpus data - swearing and abuse. In J. Kirk (Ed.), Corpora Galore: Analyses and Techniques in Describing English (pp. 45-55). Amsterdam: Rodopi.

McEnery, A., Baker, J. P., \& Hardie, A. (2000b). Swearing and abuse in Modern British English. In B. Lewandowska-Tomaszczyk \& P. J. Melia (Eds.), PALC' 99: Practical Applications in Language Corpora (pp. 37-48). Berlin: Peter Lang.

McEnery, A., \& Xiao, Z. (2004). Swearing in Modern British English: The case of fuck in the BNC. Language and Literature, 13(3), 235-268. 
Mishne, G., \& Glance, N. (2006). Leave a reply: An analysis of weblog comments. Third Annual Workshop on the Weblogging Ecosystem (WWW 2006).

Mohr, M. (2013). Holy Shit. A Brief History of Swearing. Oxford: Oxford University Press.

Nardi, B. A., Schiano, D. J., Gumbrecht, M., \& Swartz, L. (2004). Why we blog. Communications of the ACM, 47(12), 41-46.

Nigam, K., \& Hurst, M. (2004). Towards a robust metric of opinion. In Proceedings of the AAAI Spring Symposium on Exploring Attitude and Affect in Text. Retrieved from http://www.kamalnigam.com/papers/metric-EAAT04.pdf (last accessed February 2016).

Renouf, A. (1996). The ACRONYM project: Discovering the textual thesaurus. In I. Lancashire, C. Meyer \& C. Percy (Eds.), Synchronic Corpus Linguistics: Papers from English Language Research on Computerized Corpora (ICAME 16) (pp. 171-187). Amsterdam: Rodopi.

Renouf, A., \& Bauer, L. (2001). Contextual clues to word-meaning. International Journal of Corpus Linguistics, 5(2), 231-258.

Renouf, A., \& Kehoe, A. (2013). Filling the gaps: Using the WebCorp Linguist's Search Engine to supplement existing text resources. International Journal of Corpus Linguistics, 18(2), 167-198.

Romero-Trillo, J. (Ed.) (2008). Pragmatics and Corpus Linguistics. A Mutualistic Entente. Berlin: Mouton de Gruyter.

Thelwall, M. (2008). "Fk yea I swear": Cursing and gender in MySpace. Corpora, 3(1), 83-107.

Upadhyay, S. R. (2010). Identity and impoliteness in computer-mediated reader responses. Journal of Politeness Research, 6(1), 105-127. 
Appendix. Full list of swearwords included in our study

\begin{tabular}{|c|c|}
\hline Head & Pattern matched \\
\hline arse & arse/arses/arsed/arsehole*/ass/asses/assed/asshat*/asshole* \\
\hline balls & balls \\
\hline bastard & bastard/bastards \\
\hline bimbo & bimbo/bimbos \\
\hline bitch & bitch/bitches/biatch/biatches \\
\hline bloody & bloody \\
\hline bollock & bollock* \\
\hline bonk & bonk/bonks/bonking \\
\hline boob & boob/boobs \\
\hline bugger & bugger/buggers \\
\hline butt & butt/butts/butthead/buttheads/butthole/buttholes \\
\hline chav & chav/chavs \\
\hline christ & christ \\
\hline cock & cock/cocks \\
\hline coon & coon/coons \\
\hline cow & cow/cows \\
\hline crap & crap* \\
\hline cretin & cretin* \\
\hline cunt & cunt* \\
\hline damn & $*$ damn* \\
\hline dick & dick/dicks/dickhead/dickheads/dickwad \\
\hline dyke & dike/dikes/dyke/dykes \\
\hline dork & dork/dorks/dorky \\
\hline douche & douche* \\
\hline dumb & dumb/dumbass/dumbasses \\
\hline fag & fag/fags/faggot/faggots \\
\hline fanny & fannies/fanny \\
\hline fart & fart/farts \\
\hline fatass & fatass \\
\hline ffs & ffs \\
\hline fuck & fuck* \\
\hline gay & gay \\
\hline git & git/gits \\
\hline $\operatorname{god}$ & god \\
\hline hell & hell \\
\hline ho & ho/hos/hoe/hoes \\
\hline homo & homo/homos \\
\hline hussy & hussies/hussy \\
\hline idiot & idiot/idiots \\
\hline imbecile & imbecile* \\
\hline jeez & jeez \\
\hline jerk & jerk* \\
\hline
\end{tabular}




\begin{tabular}{ll} 
jesus & jesus \\
jew & jew \\
moron & moron* \\
motherfucker & motherfuck*/mofo* \\
nigger & nigga/niggas/niggah/niggahs/niggaz/nigger/niggers/nigguh/nigguhs \\
omg & omg \\
paki & paki/pakis \\
pig & pig/pigs \\
pillock & pillock/pillocks \\
pimp & pimp/pimps \\
piss & piss* \\
poof & poof* \\
prat & prat/prats \\
prick & prick/pricks \\
pussy & pussies/pussy \\
queer & queer/queers \\
retard & retard/retards/retarded \\
screw & screw/screws/screwed/screwing \\
shag & shag/shags/shagged/shagging \\
shit & *shit* \\
skank & skank* \\
slag & slag/slags/slagged \\
slapper & slapper/slappers \\
slut & slut/sluts \\
sod & sod/sods \\
sonofabitch & sonofabitch/son-of-a-bitch \\
spastic & spastic/spastics \\
suck & suck/sucks/sucker/suckers \\
swine & swine/swines \\
tart & tart/tarts/tarty \\
tit & tit/tits/titties \\
tosser & tosser/tossers \\
turd & turd/turds \\
twat & twat* \\
wank & wank* \\
whore & whore \\
wtf & wtf \\
wuss & wuss* \\
\hline &
\end{tabular}


Authors' addresses

Ursula Lutzky

Vienna University of Economics and Business

Welthandelsplatz 1

1020 Vienna

Austria

ursula.lutzky@wu.ac.at

Andrew Kehoe

School of English

Birmingham City University

Curzon Building

4 Curzon Street

Birmingham B4 7BD

United Kingdom

andrew.kehoe@bcu.ac.uk 